\title{
Clinical Assessment of New Topical Cream Containing Two Essential Oils Combined with Tretinoin in the Treatment of Acne
}

This article was published in the following Dove Press journal: Clinical, Cosmetic and Investigational Dermatology

\author{
Vittorio Mazzarello (D) \\ Elisabetta Gavini (iD ${ }^{2}$ \\ Giovanna Rassu (iD ${ }^{2}$ \\ Matthew Gavino Donadu (iD) 1,2 \\ Donatella Usai' \\ Gabriella Piu' \\ Valeria Pomponi ${ }^{1}$ \\ Federica Sucato ${ }^{3}$ \\ Stefania Zanetti ${ }^{1}$ \\ Maria Antonia Montesu ${ }^{3}$ \\ 'Skinlab, Department of Biomedical \\ Sciences, University of Sassari, Sassari, \\ Italy; ${ }^{2}$ Departmentof Chemistry and \\ Pharmacy, University of Sassari, Sassari, \\ Italy; ${ }^{3}$ Department of Medical, Surgical \\ and Experimental Sciences, University of \\ Sassari, Sassari, Italy
}

Background: Acne is a frequent adolescent disease characterized by inflammatory and noninflammatory lesions whose topical treatment very often presents adverse phenomena such as irritation or resistance to antibiotics that reduce the patient's compliance. The purpose of this study is to compare a commercial product (Acnatac gel) based on clindamycin-tretinoin (CTG) with a galenic compound containing 2 essential oils (Myrtus communisL. and Origanum vulgare) and tretinoin (MOTC) to evaluate its anti-acne effectiveness and action on the microclimate of the skin. Methods: Sixty volunteers were randomly divided into an A group using MOTC and a B group, as a positive control, using CTG. The effectiveness was assessed with non-invasive skin analysis (Sebumeter, $\mathrm{pH}$ meter, Tewameter and Mexameter) and the counts of the number of lesions, after 15 and 30 days.

Results: In both groups, there is a worsening of transepidermal water loss (TEWL) due to tretinoin. MOTC has improved, starting from 15 days of treatment, the papular erythema ( $p=0.0329 \mathrm{vs}$ CTG) and has reduced at all times even the rashes of retinoids present in the healthy perilesional skin ( $p=0.0329$ and $p=0.0017$, respectively, at 15 and 30 days).

Conclusion: MOTC has shown, compared to Acnatac, to have anti-acne efficacy and to possess an anti-inflammatory activity, due to essential oils, able to reduce in vivo erythematous lesions and those induced by retinoids.

Keywords: acne, non-invasive skin analysis, essential oils

\section{Introduction}

Acne is a frequent adolescent disease that can also occur in adulthood in women. The clinical aspect is polymorphic due to the presence of both inflammatory and non-inflammatory lesions frequently associated with scars. ${ }^{1}$

Its pathogenesis is complex and multifactorial and the most important factors are seborrhea, hyperkeratinization of the follicular isthmus, bacterial colonization of the hair follicle (especially Propionibacterium acnes, Staphylococcus aureus and Staphylococcus epidermidis) and release of inflammatory cytokines. ${ }^{2,3}$ Acne presents several clinical variants that can be solved with specific therapies. In almost all forms, it is preferable to start with topical therapy and in the event of failure, systemic therapy based on antibiotics or retinoids can be established. The most frequently used topical agents are antibiotics, alpha-hydroxy acids, azelaic acid, benzoyl peroxide, keratolytics and retinoids.

All topical products exhibit adverse skin phenomena that reduce the patient's compliance. Retinoids and benzoyl peroxide cause skin irritation; azelaic acid,
Correspondence: Matthew Gavino Donadu Department Chemistry and Pharmacy,

School of Specialization of Hospital

Pharmacy, University of Sassari, Via Vienna 2, Sassari, Italy

Tel +39079228463

Email mdonadu@uniss.it 
keratolytics and alpha-hydroxy acids can cause a stinging sensation; while antibiotics in recent years have become increasingly ineffective due to the appearance of resistant strains. $^{4}$

For these reasons, it is necessary to find new natural products that can replace, with equal or greater efficacy, the molecules present today in topical preparations, in order to avoid resistance phenomena or reduce irritating or stinging effects. The purpose of this study is to compare a commercial product based on clindamycin-tretinoin with a galenic compound containing 2 essential oils and tretinoin to evaluate its anti-acne effectiveness and action on the microclimate of the skin.

\section{Methods}

Origanum vulgare and Myrtus communisL. essential oils were purchased from Specchiasol S.r.l. (Bussolengo, Italy), and from Erbe di Sardegna (Tempio Pausania, Italy), respectively. Tretinoin was obtained from Sigma Aldrich (Milan, Italy). Macadamia oil was bought from Farmalabor (Canosa di Puglia, Italy). Fitalite ${ }^{\mathrm{TM}}$, a natural hydrophilic gel cream base containing purified water, phytosomes, lubricant, rheology enhancer, vitamin E, preservatives, was purchased from Fagron (Rotterdam, the Netherlands).

Cream was prepared by dispersing $0.74 \%(\mathrm{w} / \mathrm{w})$ of Origanum vulgare essential oil, 3.15\% (w/w) of Myrtus communisL. essential oil, $0.025 \%(\mathrm{w} / \mathrm{w})$ of tretinoin and $5 \%$ of Macadamia in Fitalite ${ }^{\mathrm{TM}}$ cream base. All components were gradually added under constant homogenization using a bench top laboratory mixer. During the preparation, the cream was protected from light.

Cream was packaged in $10 \mathrm{~mL}$ opaque white plastic tubes, to limit the possible contamination of the formulation due to an incorrect manipulation by the patients.

The stability of cream prepared was evaluated by centrifugation test. Samples of cream $(2 \mathrm{~g})$ were stored at $4^{\circ} \mathrm{C}$, $20^{\circ} \mathrm{C}$ and $40^{\circ} \mathrm{C}$ for 4 weeks. At each time point, samples were centrifuged at $3000 \mathrm{rpm}$ for $30 \mathrm{~min}$ at $20^{\circ} \mathrm{C}$. Phase separation was reported as percentage of stability. ${ }^{5}$

Data obtained were compared with those observed at time 0 . The $\mathrm{pH}$ of cream was also measured at each time point. The Preservative efficacy testing (PET) (challenge test) was performed following the guidelines of the United States Pharmacopeia (USP).

All subjects had a complete clinical history, while physical examinations and skin swabs were performed to confirm the diagnosis. Experienced bacteriologists performed laboratory analyses and were involved in data collection and data entry.

A collection of 8 clinical isolates belonging to 3 different species of bacteria was selected for this study: $S$. aureus (3), S. epidermidis (3), P. aeruginosa (2) (Table 1). The isolates were cultured from specimens of hospitalized patients at the Department of Medical, Surgical and Experimental Sciences of the University of Sassari.

\section{Study Design}

The comparative, randomized, single-center (Skinlab) and single-blind study was carried out on patients enrolled from the Dermatological Clinic - University of Sassari during the autumn-winter 2018-2019 period.

The inclusion criteria for the volunteers were: 14-34 year olds of both sexes, in good health without diseases and topical-systemic therapies for at least 3 months, with mildmoderate facial acne (with a maximum of 20-50 papules, pustules and comedones, some scarring results in the erythematous phase, absence of nodulocystic lesions). ${ }^{6}$ The following were excluded: minors, allergic or sensitive skin subjects, pregnant or lactating women or with polycystic ovary syndrome.

Sixty volunteers were enrolled, randomly divided into two groups of 30 .

Group A used a cream containing 3.74\% of Myrtus communis L. essential oil, 0.1\% Origanum vulgare essential oil and 0.025 tretinoin (MOTC).

Group B (positive control) applied a pharmaceutical product (Acnatac gel, Meda Pharma GmbH, Bad Homburg, Germany) based on $1 \%$ clindamycin and $0.025 \%$ tretinoin (CTG).

Each participant was explained how to use the product (apply once a day in the evening after washing the face), it was advised not to use any other topical product during the whole treatment after which he signed an informed consent.

The blinded investigators evaluated the volunteers at the time of inclusion (t0), after 15 (t15) and 30 (t30) days. During each clinical visit, instrumental measurements and macro photography were also carried out.

The clinical visit had the purpose, to evaluate the effectiveness of the treatment, to count the number of lesions present on the face of the volunteers in all phases of the study: the comedones $(\mathrm{CN})$, the papules (PPN), and the pustules (PSN). These parameters were used to obtain: the total lesion count $(\mathrm{TLC}=\mathrm{PPN}+\mathrm{PSN}+\mathrm{CN})$ and the acne severity index $(\mathrm{ASI}=\mathrm{PPN}+(\mathrm{PSN} \times 2)+(\mathrm{CN} / 4))$. The values of PPN, PSN, CN, ASI and TLC at t0 were 
Table I Susceptible Test to Different Antibiotics

\begin{tabular}{|c|c|c|c|c|c|c|c|c|}
\hline & S. aureus & P. aeruginosa & P. aeruginosa & S. epidermidis & S. epidermidis & S. aureus & S. aureus & S. epidermidis \\
\hline Amikacin & S & S & S & S & S & S & // & S \\
\hline Amox/Kclav & $\mathrm{R}$ & $\mathrm{R}$ & $\mathrm{R}$ & $\mathrm{R}$ & $\mathrm{R}$ & $\mathrm{R}$ & $R$ & $\mathrm{R}$ \\
\hline Amp/Sulbactam & $R$ & $R$ & $\mathrm{R}$ & $R$ & $\mathrm{R}$ & $\mathrm{R}$ & $\mathrm{R}$ & $\mathrm{R}$ \\
\hline Ampicillin & $\mathrm{R}$ & $R$ & $\mathrm{R}$ & $R$ & $\mathrm{R}$ & $\mathrm{R}$ & $\mathrm{R}$ & $R$ \\
\hline Aztreonam & s & s & s & s & s & s & /l & s \\
\hline Cefepime & S & S & S & S & $S$ & $S$ & /l & S \\
\hline Cefpodoxime & $\mathrm{R}$ & $\mathrm{R}$ & $\mathrm{R}$ & $\mathrm{R}$ & $\mathrm{R}$ & $\mathrm{R}$ & $\mathrm{R}$ & $\mathrm{R}$ \\
\hline Ceftazidime & S & S & S & S & $S$ & $S$ & /I & $S$ \\
\hline Ceftriaxone & $R$ & $R$ & $R$ & $R$ & $\mathrm{R}$ & $R$ & $R$ & $R$ \\
\hline Cefuroxime & $\mathrm{R}$ & $\mathrm{R}$ & $\mathrm{R}$ & $\mathrm{R}$ & $\mathrm{R}$ & $\mathrm{R}$ & $\mathrm{R}$ & $\mathrm{R}$ \\
\hline Chloramphenicol & $R$ & $\mathrm{R}$ & $R$ & $R$ & $R$ & $R$ & $\mathrm{R}$ & $\mathrm{R}$ \\
\hline Colistin & S & S & S & S & /I & $S$ & /l & S \\
\hline Doripenem & S & S & S & S & S & $S$ & $R$ & S \\
\hline Fosfomycin & $R$ & $R$ & $R$ & $R$ & $R$ & $R$ & $R$ & $R$ \\
\hline Imipenem & S & S & $\mathrm{S}$ & $\mathrm{S}$ & $S$ & $S$ & $\mathrm{R}$ & $\mathrm{S}$ \\
\hline Meropenem & S & $\mathrm{S}$ & $S$ & $S$ & $S$ & $S$ & /I & $S$ \\
\hline Norfloxacin & $R$ & $R$ & $R$ & $R$ & $R$ & $R$ & $R$ & $R$ \\
\hline Pip/Tazo & S & S & S & S & $R$ & $S$ & /I & S \\
\hline Piperacillin & S & S & S & S & $R$ & $S$ & /I & $S$ \\
\hline Tetracyclin & $\mathrm{R}$ & $\mathrm{R}$ & $\mathrm{R}$ & $\mathrm{R}$ & $\mathrm{R}$ & $\mathrm{R}$ & $\mathrm{R}$ & $\mathrm{R}$ \\
\hline Tobramycin & $S$ & S & S & S & $S$ & $S$ & /I & $S$ \\
\hline Trime/Sulfa & $R$ & $R$ & $R$ & $R$ & $R$ & $R$ & $R$ & $R$ \\
\hline
\end{tabular}

Notes: $\mathrm{R}=$ Resistant; $\mathrm{S}=$ Sensible; $/ /=$ not tested.

considered to be $100 \%$. In the following times, any reductions in the lesions were considered as a percentage of improvement.

The instrumental measurements were intended to evaluate the modifications of some biophysical parameters induced by the treatment. Using instrumental measurements, we assessed the amount of skin sebum, $\mathrm{pH}$, erythema index and transepidermal water loss (TEWL) using Sebumeter SM825, pH meter PH900, Mexameter MX16 and Tewameter TM300 (Courage + Khazaka Electronic GmbH, Cologne, Germany). Sebum, $\mathrm{pH}$ and TEWL were measured on healthy skin areas free from acne lesions. Erythema index was assessed on both healthy skin and inflamed papules. All measurements were performed randomly on one of the cheeks through 3 measurements per probe, subsequently calculating the average value. On each volunteer the areas analyzed, during all times of the trial, have always been the same.

In addition, to evaluate the results, macro-photographs of the face of the volunteers were also made at the beginning and end of the treatment, using Visioface 1000D (Courage + Khazaka Electronic GmbH, Cologne, Germany).

Approval from the Ethics Committee/Institutional Review Board of the "Azienda Tutela della Salute"
Sardegna Protocol number ${ }^{\circ} 2490 / C E$, Sassari, Italy, was obtained and the study was conducted in complete agreement with the principles of the Declaration of Helsinki. Each participant received detailed information and provided written informed consent before inclusion. It is confirmed in the manuscript that a parent or guardian has provided written informed consent to all participants under the age of 18 .

\section{Statistical Analysis}

All results were compared with the baseline measurement at each time, using Paired t-tests or a non-parametric test (Wilcoxon test) if the data did not have a normal distribution after using Shapiro-Wilk test.

All statistical tests were two-tailed tests and p-values $\leq 0.05$ were considered statistically significant. All data analyses were performed using an SPSS statistical package. All data were submitted as mean \pm standard deviation (SD) and, beyond measured value, differences versus baseline or inter-group were reported.

\section{Results}

The cream base is able to incorporate Macadamia and essential oils, preserving its original texture. The cream 
remains stable for 4 weeks at all temperature conditions considered: no oil phase separation was observed. The $\mathrm{pH}$ of cream is $5.0 \pm 0.05$ and does not change during the time.

On the basis of this results, the expiration date of the product was established after 4 weeks from the production. Furthermore, though the temperature conditions do not affect the stability of cream, it was chosen to store the cream at $4{ }^{\circ} \mathrm{C}$ for slightly increase the viscosity and, then, improving the compliance of patients. The essential oils have been included in the galenic formulation following the concentrations proportional to the Minimum Bactericidal Concentration.

Table 2 shows the demographic characteristics of volunteers with acne divided into 2 groups that show no significant differences between them $(p=0.0291)$, demonstrating success by randomization. No patient from either group left the investigation.

The instrumental and clinical results obtained in the study are shown in Tables 3 and 4.

The instrumental values studied show some differences between the two groups. No sebometry and $\mathrm{pH}$ changes were observed in both groups during the study. TEWL worsened in both groups, but earlier (day 15) in the MOTC group. The MOTC formulation was better than the CTG in reducing papular erythema index after 15 days with a significant statistical difference between the groups $(\mathrm{p}=0.0329)$. The erythema in inter-papular healthy skin increases statistically significantly only in the skin treated with CTG ( $\mathrm{p}=0.0017$ at 30 days) (Table 3 ).

Both products have improved clinical parameters at each time studied and no statistically significant differences were detected in the inter-group comparison (Table 4).

\section{Discussion}

Acne is a polymorphic disease that requires combined topical treatment. The most used topical products, for mild-moderate acne, are antibiotics, antimicrobials and retinoids. Antibiotics are becoming less effective due to the emergence of resistant strains. Antimicrobials such as

Table 2 Demographic Characteristics of Patients

\begin{tabular}{|l|l|l|}
\hline & Group A & Group B \\
\cline { 2 - 3 } & $\mathbf{n}=\mathbf{3 0}$ & $\mathbf{n}=\mathbf{3 0}$ \\
\hline Male & $15(50 \%)$ & $15(50 \%)$ \\
Female & $15(50 \%)$ & $15(50 \%)$ \\
Age (mean and SD) & $14-36$ & $14-35$ \\
Acne Severity Index & $21.71 \pm 5.92$ & $20 \pm 6.4 \mathrm{I}$ \\
\hline
\end{tabular}

Table 3 Efficacy of MOTC (Myrtus communisL., Origanum vulgare and Treotinoine Cream), CTG (Clindamycin and Tretinoin Gel) in the Modification of Biophysical Parameters

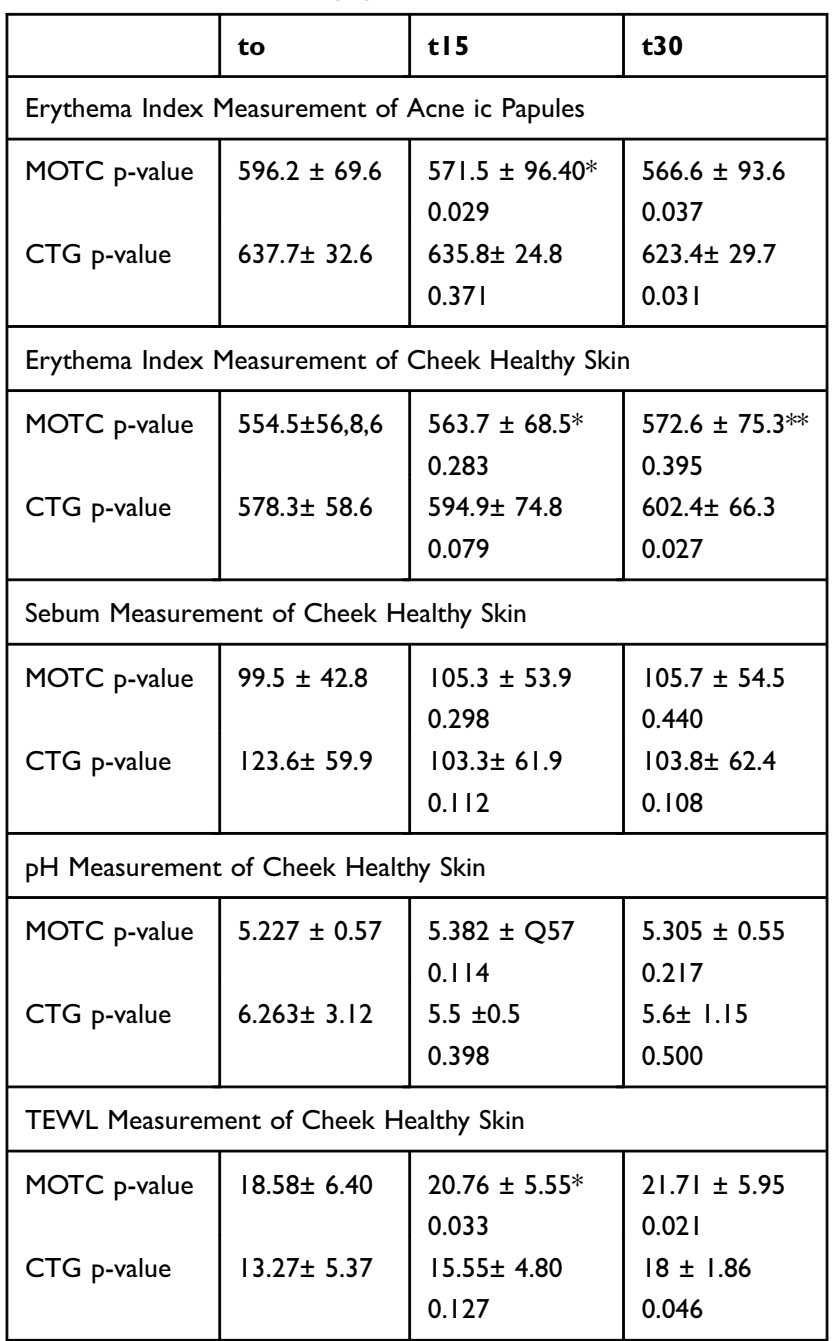

Notes: Mean with SD difference in erythema index, sebum, $\mathrm{pH}$ and TEWL (transepidermal water loss) from baseline to days 15 and 30 . Inter-group comparison: $* \mathrm{P} \leq 0.05$, **P $\leq 0.01$.

azelaic acid can develop resistance to Propionibacterium acnes in longterm use. The use of retinoids, in most cases, is complicated by an irritating dermatitis especially following sun exposure that limits their use in hot seasons.

For these reasons, we are looking for new products that can replace antibiotics and antimicrobials and among them are remedies based on botanical products or essential oils. In fact, numerous researchers have demonstrated the anti-acne efficacy of some extracts both topically and orally. ${ }^{7-16}$

The effective essential oils for acne treatment so far have been Tea tree oil, Lavender oil and Ocimum gratissimum and Ramulusmori. ${ }^{7,9,10,12,15,16}$

In a previous paper, we also demonstrated the anti-acne efficacy of an essential oil, associated with 2 plant extracts, 
Table 4 Efficacy of MOTC (Myrtus communisL., Origanum vulgare and Tretinoin Cream), CTG (Clindamycin and Tretinoin Gel) in the Reduction of Different Type Lesions

\begin{tabular}{|c|c|c|c|}
\hline & to & tI5 & $\mathbf{t 3 0}$ \\
\hline \multicolumn{4}{|c|}{$\mathrm{CN}$ Measurement } \\
\hline $\begin{array}{l}\text { MOTC p-value } \\
\text { CTG p-value }\end{array}$ & $\begin{array}{l}20.2 \pm 12.7 \\
39.3 \pm 30.8\end{array}$ & $\begin{array}{l}13.1 \pm 8.25 \\
0.143 \\
28.4 \pm 17.2 \\
0.061\end{array}$ & $\begin{array}{l}11 \pm 8.25 \\
0.043 \\
14.3 \pm 19.3 \\
0.055 \mid\end{array}$ \\
\hline \multicolumn{4}{|c|}{ PPN Measurement } \\
\hline $\begin{array}{l}\text { MOTC p-value } \\
\text { CTG p-value }\end{array}$ & $\begin{array}{l}15.1 \pm 9.58 \\
17.3 \pm 16.9\end{array}$ & $\begin{array}{l}12.2 \pm 4.82 \\
0.256 \\
15.6 \pm 14.7 \\
0.203\end{array}$ & $\begin{array}{l}8.8 \pm 5.26 \\
0.06 \mid \\
12.9 \pm 17.5 \\
0.109\end{array}$ \\
\hline \multicolumn{4}{|c|}{ PSN Measurement } \\
\hline $\begin{array}{l}\text { MOTC p-value } \\
\text { CTG p-value }\end{array}$ & $\begin{array}{l}7.4 \pm 4.40 \\
11.9 \pm 8.88\end{array}$ & $\begin{array}{l}3.3 \pm 1.56 \\
0.018 \\
5.1 \pm 3.21 \\
0.022\end{array}$ & $\begin{array}{l}3.9 \pm 2.37 \\
0.013 \\
5.5 \pm 4.14 \\
0.039\end{array}$ \\
\hline \multicolumn{4}{|c|}{ TLC Measurement } \\
\hline $\begin{array}{l}\text { MOTC p-value } \\
\text { CTG p-value }\end{array}$ & $\begin{array}{l}42.7 \pm 22.9 \\
64.6 \pm 42.8\end{array}$ & $\begin{array}{l}28.6 \pm 10.2 \\
0.037 \\
46.3 \pm 24.2 \\
0.045\end{array}$ & $\begin{array}{l}23.7 \pm 10.4 \\
0.022 \\
31.3 \pm 22.7 \\
0.005\end{array}$ \\
\hline \multicolumn{4}{|c|}{ ASI Measurement } \\
\hline $\begin{array}{l}\text { MOTC p-value } \\
\text { CTG p-value }\end{array}$ & $\begin{array}{l}34.9 \pm 19.0 \\
49.9 \pm 28.1\end{array}$ & $\begin{array}{l}22.0 \pm 4.90 \\
0.040 \\
32.2 \pm 17.6 \\
0.024\end{array}$ & $\begin{array}{l}19.3 \pm 8.30 \\
0.023 \\
27.1 \pm 22.5 \\
0.011\end{array}$ \\
\hline
\end{tabular}

Notes: Mean with SD difference in number of comedones $(\mathrm{CN})$, papules (PPN), pustules (PSN), acne severity index (ASI) and total lesion count (TLC) from baseline to days 15 and 30 .

compared to erythromycin in cream to assess, in vivo, its actual antibiotic effect. ${ }^{17}$ In this study, however, we decided to test 2 essential oils extracted from typical Sardinian plants, never used in the treatment of acne, with the aim of assessing whether, as a result of association with a retinoid, they can not only have an antimicrobial activity but also mitigate the irritating effects due to retinoids. The MOTC contains Myrtus communisL. and Origanum vulgare essential oils associated with tretinoin which is a retinoid. The two essential oils have been selected because their antibacterial and anti-inflammatory properties have been demonstrated.

The antibacterial activity on the main skin bacteria has been demonstrated by us in vitro while the one against propionibacterium by other researchers. ${ }^{18}$ In addition, in a previous study, the essential oil of Origanum vulgare in nanoemulsion, tested in an acne animal mouse model, has been shown to be a potential anti-acne product. ${ }^{18}$ The myrtle in previous studies has also shown in vitro a potential anti-acne activity associated with other plant extracts19 or antibiotics..$^{19,20}$

The anti-inflammatory action of the 2 essential oils has been demonstrated in vitro by other authors. ${ }^{21,22}$

In our study, MOTC was compared to a commercial product (Acnatac) containing clindamycin and tretinoin whose anti-acne efficacy has already been demonstrated previously. ${ }^{23}$ We chose a clindamycin-based product because in recent years it has replaced erythromycin, which is increasingly showing phenomena of bacterial resistance. ${ }^{24}$

Our results have shown that MOTC product compared to CTG has the same anti-acne efficacy and increased antiinflammatory activity. In particular, the count of individual acne lesions and the ASI and TLC index improved in both groups with no significant differences in group comparison.

In the instrumental tests both MOTC and CTG have shown to respect the hydrolipidic film by not changing the $\mathrm{pH}$ and sebum. The group that used MOTC showed no significant differences in erythema of the cheek skin unlike the other group that presented skin irritation after 30 days of use of CTG product (Figure 1).

Due to the presence of tretinoin, both products have altered the skin barrier as already demonstrated by other authors. ${ }^{25}$ The early action on papular erythema may be due to the fact that oregano is able to suppress the inflammation induced by propionibacterium. ${ }^{26}$ In conclusion our in vivo study showed, in our sample with mild-moderate acne, that essential oils of myrtle and oregano have antibiotic and antiinflammatory properties, managing to improve acne lesions and retinoid erythema. Therefore, due to this double activity, they could be used, in substitution of the associated antibiotics, in the formulations with retinoids.

\section{Limit}

Our work has 2 limitations: the low number of volunteers and the standardization of essential oils.

This study was conducted on a limited sample of 30 subjects and a positive control and nonparametric tests with post hoc analysis were used to give value to the trial.

There is nothing wrong with carrying out small, welldesigned studies because the data obtained, after careful interpretation, can be used in the future to design more extensive confirmatory studies. 


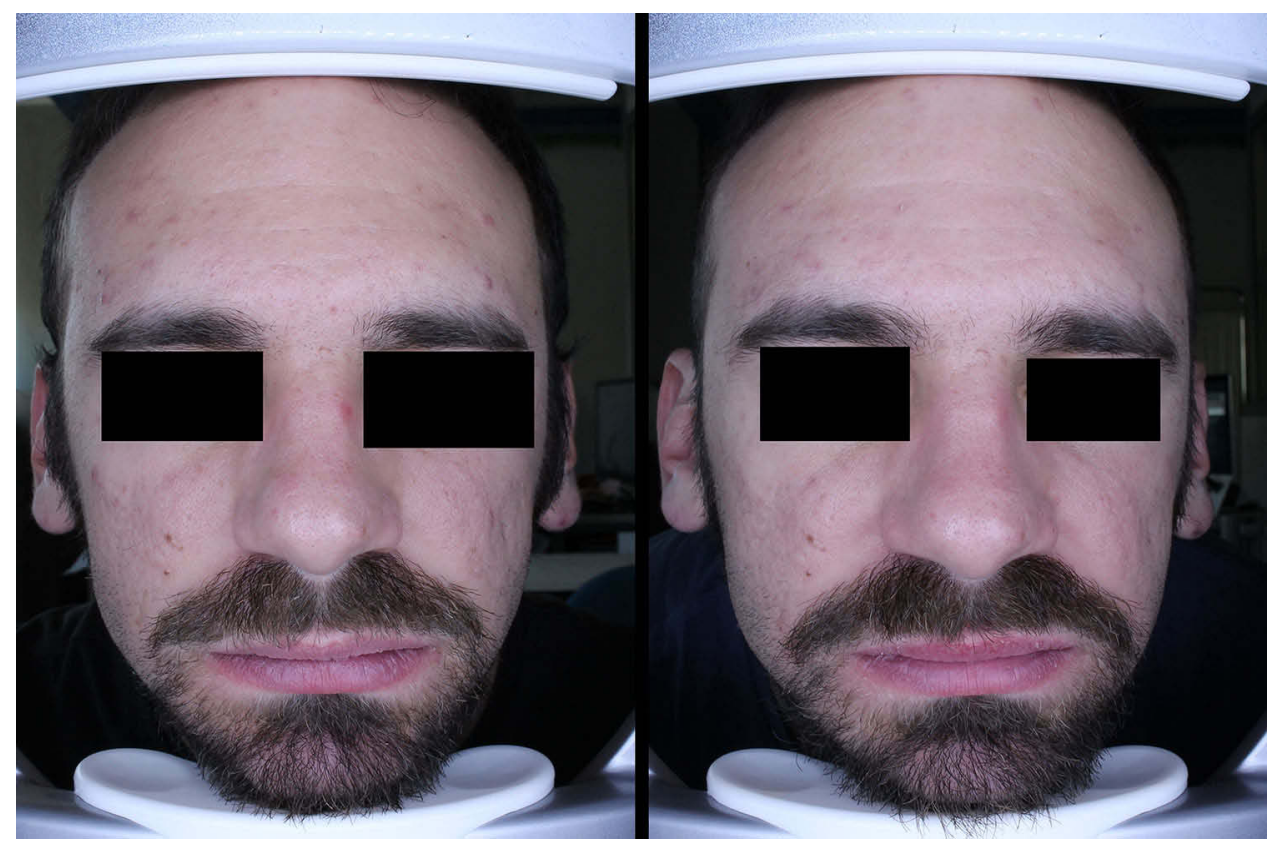

Figure I Clinical efficacy of three formulations in the reduction of lesions and erythema after 15 days of treatment.

Essential oils are difficult to standardize because they have a chemical composition that can vary depending on the growing conditions (production site), genetics and harvesting of plants. Therefore, the results obtained refer to the chemical characteristics of our 2 essential oils and the concentration we used. Further studies would be needed to see if the same results can be obtained with other cultivars.

\section{Acknowledgments}

We wish to thank Dr. Giovanni Deligia who passed away during the course of this study.

\section{Funding}

This article has no funding source.

\section{Disclosure}

The authors report no conflicts of interest in this work.

\section{References}

1. Williams HC, Dellavalle RP, Garner S. Acne vulgaris. Lancet. 2012;379:361-372. doi:10.1016/S0140-6736(11)60321-8

2. Bek-Thomsen M, Lomholt HB, Kilian M. Acne is not associated with yet-uncultured bacteria. J Clin Microbiol. 2008;46:3355-3360. doi:10.1128/JCM.00799-08

3. Contasot E, French LE. New insights into acne pathogenesis: Propionibacterium acnes activates the inflammasome. J Invest Dermatol. 2014;134:310-313. doi:10.1038/jid.2013.505
4. Ross JJ, Snelling AM, Carnegie E, et al. Antibiotic-resistant acne: lessons from Europe. Brit J Dermatol. 2003;148:467-478. 5. doi:10.1046/j.1365-2133.2003.05067.x

5. Spada G, Gavini E, Cossu M, Rassu G, Carta A, Giunchedi P. Evaluation of the effect of hydroxypropyl- $\beta$-cyclodextrin on topical administration of milk thistle extract. Carbohydr Polym. 2013;92 (2013):40-47. doi:10.1016/j.carbpol.2012.09.018

6. Cunliffe W, Gollnick HPM. Topical therapy. In: Cunliffe W, Gollnick HP, editors. Acne Diagnosis and Management. USA: Martin Dunitz Press; 2001:107-14. 7.

7. Bassett IB, Pannowitz DL, Barnetson RS. A comparative study of tea-tree oil versus benzoylperoxide in the treatment of acne. Med J Aust. 1990;153 (8):455-458. doi:10.5694/j.1326-5377.1990.tb126150.x

8. Lalla JK, Nandedkar SY, Paranjape MH, Talreja NB. Clinical trials of ayurvedic formulations in the treatment of acne vulgaris. J Ethnopharmacol. 2001;78(1):99-102. (). doi:10.1016/S0378-8741(01) 00323-3

9. Orafidiya LO, Agbani EO, Oyedele AO, Babalola OO, Onayemi O. Preliminary clinical tests on topical preparations of Ocimum gratis-simum Linn leaf essential oil for the treatment of acne vulgaris. Clin Drug Investig. 2002;22(5):313-319. doi:10.2165/00044011200222050-00005

10. Yoo J, Park S, Hwang I. A clinical study on the effect of a cream containing Ramulus mori extract and tea tree oil on acne vulgaris and aerobic skin flora. Korean J Dermatol. 2003;41:1136-1141.

11. Orafidiya L, Agbani EO, Oyedele AO, Babalolab OO, Onayemic O, Aiyeduna FF. The effect of Aloe vera gel on the anti-acne properties of the essential oil of Ocimum gratissimum Linn leaf - a preliminary clinical investigation. Int J Aromather. 2004;14(1):15-21. doi:10.1016/ j.ijat.2003.12.005

12. Enshaieh S, Jooya A, Siadat AH, Iraji F. The efficacy of $5 \%$ topical tea tree oil gel in mild to moderate acne vulgaris: a randomized, double-blind placebo-controlled study. Indian J Dermatol Venereol Leprol. 2007;73(1):22-25. doi:10.4103/0378-6323.30646

13. Balambal R, Thiruvengadam KV, Kameswarant L, Janaki VR, Thambiah AS.Ocimum basilicum in acne vulgaris a controlled comparison with a standard regime. J Assoc Physicians India. 1985;33 (8):507-508. 
14. Sharquie KE, Noaimi AA, Al-Salih MM.Topical therapy of acne vulgaris using $2 \%$ tea lotion in comparison with $5 \%$ zinc sulphate solution. Saudi Med J. 2008;29(12):1757-1761.

15. Kim B, Shin S. Antimicrobial and improvement effects of tea tree and lavender oils on acne lesions. J Convergence Inf Technol. 2013;8:339-345.

16. Kwon HH, Yoon JY, Park SY, Min S, Suh DH. Comparison of clinical and histological effects between lactobacillus-fermented Chamaecyparis obtusa and tea tree oil for the treatment of acne: an eight-week double-blind randomized controlled split-face study. Dermatology. 2014;229(2):102-109. doi:10.1159/000362491

17. Mazzarello V, Donadu MG, Ferrari M, et al. Treatment of acne with a combination of propolis, tea tree oil, and Aloe vera compared to erythromycin cream: two double-blind investigations. Clin Pharmacol. 2018;13(10):175-181.

18. Taleb MH, Abdeltawab NF, Shamma RN, et al. Essential oil as a potential anti-acne topical nanoemulsion-in vitro and in vivo study. Molecules. 2018;23(9). doi:10.3390/molecules23092164

19. Kılıç S, Okullu SO, Kurt O, et al. Efficacy of two plant extracts against acne vulgaris: initial results of microbiological tests and cell culture studies. J Cosmet Dermatol. 2019;18(4):1061-1065. doi:10.1111/jocd.12814

20. Fiorini-Puybaret C, Aries MF, Fabre B, et al. Pharmacological properties of Myrtacine ${ }^{\circledR}$ and its potential value in acne treatment. Planta Med. 2011;77(14):1582-1589. doi:10.1055/s-0030-1270955
21. De Santis F, Poerio N, Gismondi A, et al. Hydroalcoholic extract from origanum vulgare induces a combined anti-mycobacterial and anti-inflammatory response in innate immune cells. PLoS One. 2019;14(3):e0213150. doi:10.1371/journal.pone.0213150

22. Cruciani S, Santaniello S, Garroni G, et al. Myrtus polyphenols, from antioxidants to anti-inflammatory molecules: exploring a network involving cytochromes P450 and vitamin D. Molecules. 2019;24(8). doi:10.3390/molecules24081515

23. Del Rosso JQ. Clindamycin phosphate-tretinoin combination gel revisited: status report on a specific formulation used for acne treatment. Cutis. 2017;99(3):179-183.

24. Austin BA, Fleischer AB Jr. The extinction of topical erythromycin therapy for acne vulgaris and concern for the future of topical clindamycin. J Dermatolog Treat. 2017;28(2):145-148. doi:10.1080/ 09546634.2016.1214234

25. Goreshi R, Samrao A, Ehst BD. Un confronto in doppio cieco, randomizzato, bilaterale dell'irritazione cutanea dopo l'applicazione della combinazione di prodotti per l'acne clindamicina/tretinoina e perossido di benzoile/adattoalene. J Drugs Dermatol. 2012;11 (12):1422-1426.

26. Chuang LT, Tsa TH, Lien TJ, et al. Ethanolic extract of origanum vulgare suppresses propionibacterium acnes-induced inflammatory responses in human monocyte and mouse ear edema models. Molecules. 2018;23(8):1987. doi:10.3390/molecules23081987

\section{Publish your work in this journal}

Clinical, Cosmetic and Investigational Dermatology is an international, peer-reviewed, open access, online journal that focuses on the latest clinical and experimental research in all aspects of skin disease and cosmetic interventions. This journal is indexed on CAS.
The manuscript management system is completely online and includes a very quick and fair peer-review system, which is all easy to use. Visit http://www.dovepress.com/testimonials.php to read real quotes from published authors. 